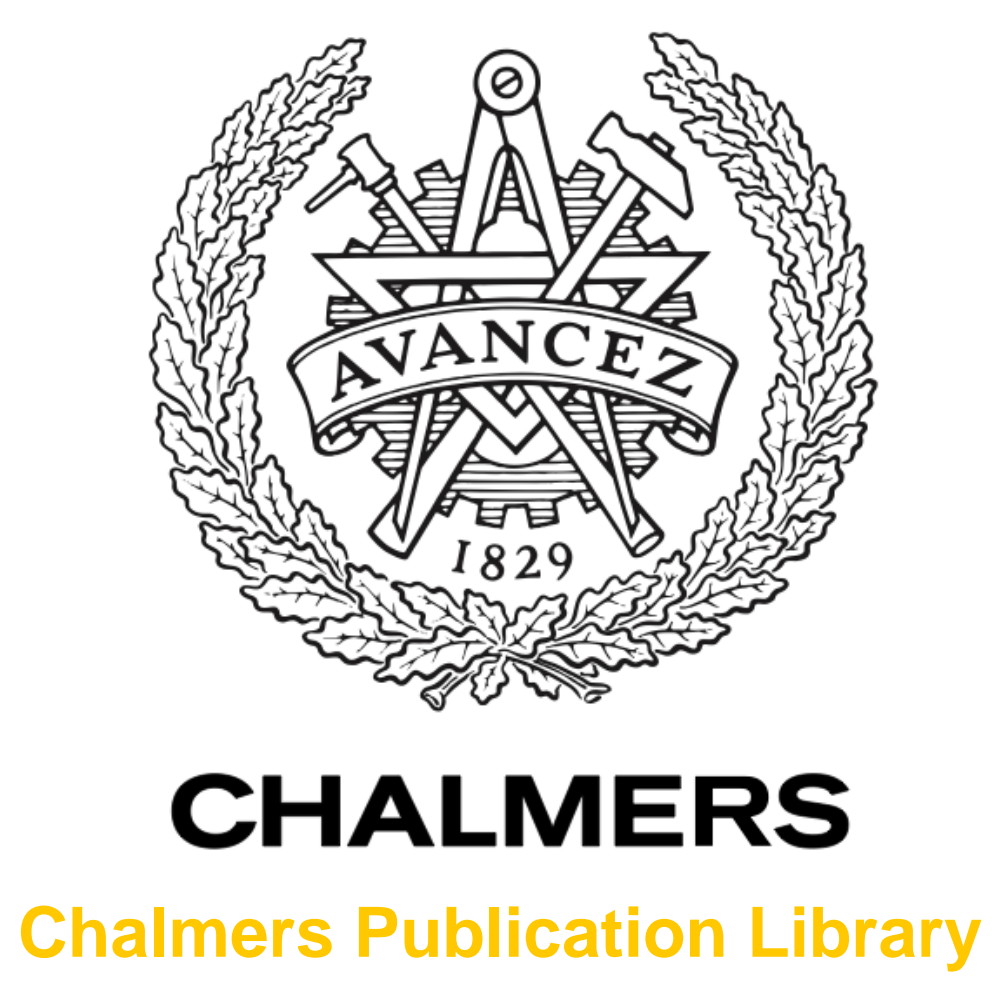

\title{
THE IMPACT OF ZEOLITES DURING CO-COMBUSTION OF MUNICIPAL SEWAGE SLUDGE WITH ALKALI AND CHLORINE RICH FUELS
}

This document has been downloaded from Chalmers Publication Library (CPL). It is the author's version of a work that was accepted for publication in:

\author{
Proceedings of the 20th International Conference on Fluidized Bed Combustion in Xi:an, \\ China May 18-20, 2009 \\ Citation for the published paper: \\ Pettersson, A. ; Elled, A. ; Möller, A. et al. (2009) "THE IMPACT OF ZEOLITES DURING \\ CO-COMBUSTION OF MUNICIPAL SEWAGE SLUDGE WITH ALKALI AND \\ CHLORINE RICH FUELS". Proceedings of the 20th International Conference on Fluidized \\ Bed Combustion in Xi:an, China May 18-20, 2009, vol. 2 pp. 903-909.
}

Downloaded from: http://publications.lib.chalmers.se/publication/238143

Notice: Changes introduced as a result of publishing processes such as copy-editing and formatting may not be reflected in this document. For a definitive version of this work, please refer to the published source. Please note that access to the published version might require a subscription. 


\section{Progecalings of}

\section{the $20 \mathrm{~h}$ International conierence on}

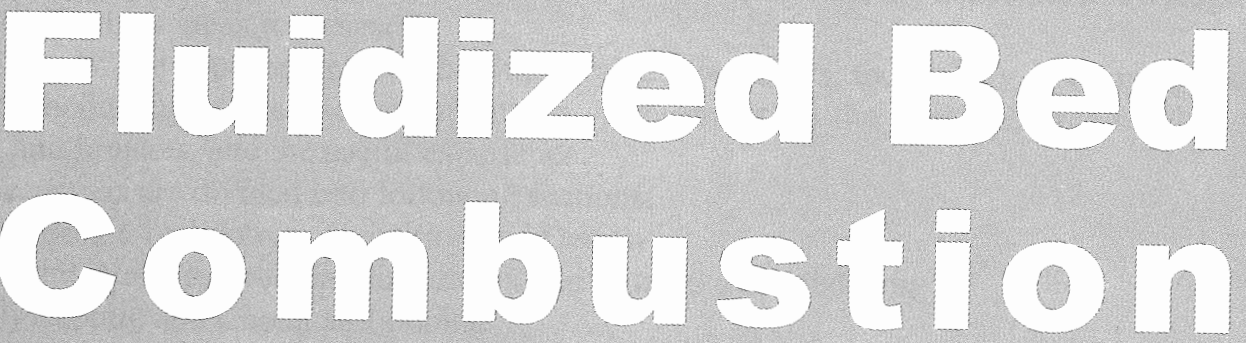

\section{(II)}

Edited by

Guangxi Yue

Hai Zhang

Changsui Zhao

Zhongyang Luo 
THE IMPACT OF ZEOLITES DURING CO-COMBUSTION OF MUNICIPAL SEWAGE SLUDGE WITH ALKALI AND CHLORINE RICH FUELS

\author{
A Pettersson ${ }^{1}$, A-L Elled ${ }^{1}$, A Möller ${ }^{3}$, B-M Steenari² L-E Åmand ${ }^{3}$ \\ ${ }^{1}$ University of Borås, SE-501 90 Borås, Sweden \\ ${ }^{2}$ Department of Chemical and Biological Engineering, Chalmers University of Technology SE-412 \\ 96 Göteborg, Sweden \\ ${ }^{3}$ Department of Energy and Environment, Chalmers University of Technology
}

\begin{abstract}
Municipal sewage sludge has proven to eliminate alkali metals and chlorine related problems during combustion of straw and refuse derived fuels (RDF). However, the mechanisms involved have not been clarified. The aim of this work was to gain more knowledge about the behaviour of sewage sludge and detergent zeolites in combustion and about their effects on alkali metal chemistry.

Co-combustion tests with combinations of municipal sewage sludge, wood and straw were carried out in a 12 MW fluidised bed (FB) boiler. In addition, a detergent zeolite, Doucil A24, was used as additive during co-combustion of wood and straw. The chemical characteristics of fuels and fly ashes were studied using several methods, such as chemical fractionation and scanning electron microscopy with element analysis by energy dispersive fluorescence detection (SEM-EDX) and X-ray diffraction (XRD).

In the co-combustion tests involving sewage sludge no $\mathrm{KCl}$ was found in the flue gas prior to the convection pass. The zeolite addition was less effective but the $\mathrm{KCl}$ concentration was reduced to some degree in favour of $\mathrm{HCl}$ compared to the reference case. Both SEM-EDX and XRD confirmed the presence of potassium-aluminium-silicates in the fly ash fraction in all cases. In addition, the laboratory study showed that Doucil A24 had the ability to capture potassium and $\mathrm{KCl}$ at temperatures in the range of $700-900^{\circ} \mathrm{C}$.
\end{abstract}

Keywords: Zeolites, alkali, chlorine, capture, fly ash

\title{
INTRODUCTION
}

At the same time as the energy consumption in the world is increasing, the reports on global warming becomes more serious, ICCP (2007). In the efforts to reduce the net emissions of green house gases new fuels and fuel mixes for heat and power production are considered. Some of these fuels contain high concentrations of alkali metals and chlorine making the utilisation of these fuels rather difficult. Fluidised bed (FB) boilers are known to be very fuel flexible, but as the combustion takes place in a sand bed, chemical interactions between bed particles and fuel ash compounds may occur. This can lead to formation of eutectic melts causing bed agglomeration and in the worst case expensive operating shut downs. Additional combustion problems as deposit formation and corrosion are also caused by alkali and chlorine.

Municipal sewage sludge has proven to have an ability to capture available alkali metal species (k and/or Na) when used as additive in combustion of straw and RDF (Davidsson et al. 2007, Pettersson et al. 2008, Elled et al. 2008). In general municipal sewage sludge contains high concentrations of $\mathrm{Si}, \mathrm{Al}, \mathrm{K}, \mathrm{S}, \mathrm{P}, \mathrm{Fe}$ and $\mathrm{Ca}$ (Eriksson, 2001). In addition the contents of ash and moisture are high. The zeolite Doucil A24 is a common component in phosphate free household detergents and thus it occurs in sewage water. The zeolites are mainly collected in the sewage sludge in the wastewater treatment plant. Zeolites are aluminium silicates and their structure are characterised by the presence of systems of interconnected cavities, tunnels, in 3D 
structures. This anionic sieve has a resulting charge and a mesh size in the molecular range making them excellent cat-ion exchangers, water softener and molecular sieves. Both Doucil A24 and its forerunner zeolite $\mathrm{A}$ (or $\mathrm{NaA}$ ) are manufactured as Na zeolites, meaning that the zeolite cavities are filled with Na-ions. These zeolites have an affinity for $\mathrm{K}^{+}, \mathrm{Ca}^{2+}$ and $\mathrm{Mg}^{2+}$ and exchange their $\mathrm{Na}^{+}$for these ions in the washing water.

The aim of this work was to investigate more closely the zeolites ability to capture alkali and chlorine in the combustion since this mechanism is suspected to be important for the effects of sewage sludge addition in combustion.

\section{EXPERIMENTAL SECTION}

\section{Boiler, sampling and analyses}

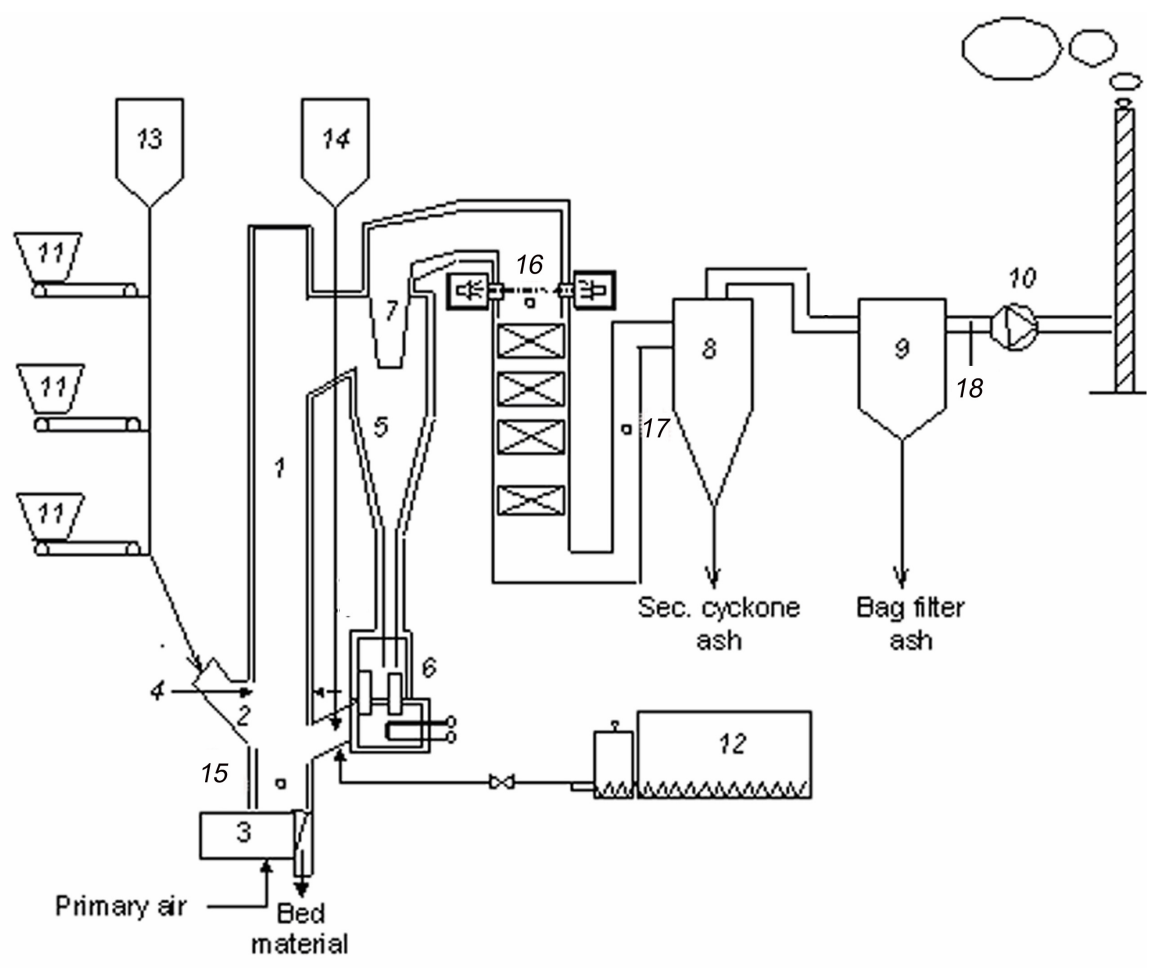

Fig. 1: The 12-MWth FBC boiler at Chalmers University of Technology
The $12 \mathrm{MW}_{\text {th }}$ circulating fluidised bed (CFB) boiler located at Chalmers University of Technology was used for the combustion tests, Fig. 1. The boiler is described by Pettersson et al. (2008). The boiler system consists of a combustion chamber (1), fuel feed chute (2), air plenum (3), secondary air inlet at $2.1 \mathrm{~m}$ (4), hot primary cyclone (5), loop seal (6), cyclone exit duct (7), cold secondary cyclone (8), bag house filter (9), flue gas recirculation fan (10), fuel bunkers (11), sludge pump (12), sand bin (13), kaolin and zeolite bin (14), sampling hole for bed material (15), measurement spot (before convection pass) IACM instrument, deposit probe and FTIR (16), measurement spot (after convection pass) FTIR (17), measurement spot (stack) FTIR (18). Fuel samples were taken at the input to the boiler. Bed samples were taken at point 15 in the bottom of the combustion chamber and from the return leg after the loop seal (6) at a temperature of $850^{\circ} \mathrm{C}$. Fly ashes were sampled from the secondary cyclone and the bag filter both at $150^{\circ} \mathrm{C}$. An air-cooled deposit probe was inserted at location 16. The probe was held at a constant temperature of $500^{\circ} \mathrm{C}$ to simulate a superheater tube. During the combustion tests the boiler was held at stable conditions with a bottom bed temperature of $850^{\circ} \mathrm{C}$ and a load of $6 \mathrm{MW}_{\text {th. }}$. The content of ash, moisture and combustibles were analysed by LECO MAC 400 proximate analyzer 785-700 system. The main elements were analysed by means of X-Ray Florescence (XRF) and the trace elements by Inductive Coupled Plasma-Mass Spectrometry (ICP-MS). Mercury was analysed by cold vaporisation. To investigate the type of binding between the elements chemical fractionation was used (Pettersson et al. 2008, Zevenhoven-Onderwater, 2001). The mineralogy of the fly ash samples were studied by X-Ray powder Diffraction (XRD) for the crystalline compounds. In addition Scanning Electron Microscopy-Energy Dispersive X-ray (SEM-EDX) was used for analyses of element 
distribution in fly ash samples.

\section{Fuels and additives}

Wood pellets, a well defined bio fuel with low ash content, was used as base fuel in the combustion tests. Different fuel mixes were combusted as shown in Table 1. To increase the alkali and chlorine concentration in the fuel mix straw was used as co-fuel. In the
Table. 1: Test series.

\begin{tabular}{l|l}
\hline Test & \\
\hline Ref & $\begin{array}{l}\text { Reference test. Combustion of wood and straw pellets. } \\
21 \text { wt-\% dry straw pellets. } \\
\text { MSS }\end{array}$ \\
Combustion of wood and straw pellets with sewage sludge. \\
21 wt-\% dry straw pellets and 12 wt-\% dry sewage sludge. \\
Zeolite & Addition of zeolite Doucil A24 to the reference test.
\end{tabular}
combustion test municipal sewage sludge was added to the reference fuel mix (MSS). The fuel properties are given in Table 2. In the third combustion test the reference fuel mix was combusted with zeolite Doucil A24 as an additive (Zeolite). The molar ratio of Doucil A24 to $\mathrm{K}$ in with fuel was 1.1 reflecting the zeolite concentration in the sewage sludge used in the combustion test MSS.

\section{Laboratory experiments}

To get a better understanding of the thermal behaviour of the zeolite Doucil A24 a laboratory study was made. Doucil A24 belongs to the same structure group as the natural zeolite Gismondite, GIS and the $\mathrm{NaA}$ and $\mathrm{CaA}$ zeolites belongs to the LTA structure group. The thermal stability of such zeolites increases as a function of the Si/Al ratio in the lattice (Schwuger, 1996). Gismondite starts to decompose and form Ca-feldspars at temperatures above $375^{\circ} \mathrm{C}$ whereas zeolites $\mathrm{NaA}$ and $\mathrm{CaA}$ start to transform to feldspathoid lattices at temperatures above approximately $700^{\circ} \mathrm{C}$ and $800^{\circ} \mathrm{C}$ respectively.

The study made here focussed on the ion-exchange and

Table.2: Average fuel properties.

\begin{tabular}{|c|c|c|c|}
\hline Fuel: & $\begin{array}{l}\text { Wood } \\
\text { pellets }^{(*)}\end{array}$ & $\begin{array}{l}\text { Sewage } \\
\text { sludge }^{(*)}\end{array}$ & Straw $^{(*)}$ \\
\hline \multicolumn{4}{|l|}{ Proximate analysis } \\
\hline Water [wt-\%. raw] & 7.9 & 73 & 8.8 \\
\hline Ash [wt-\%. dry] & 0.4 & 48 & 5.6 \\
\hline Volatiles [wt- $\%$. daf] & 90.7 & 94.8 & 81.1 \\
\hline \multicolumn{4}{|c|}{ Ultimate analysis [wt-\%. daf] } \\
\hline C & 51 & 52 & 49.4 \\
\hline $\mathrm{H}$ & 6.1 & 7.5 & 6.3 \\
\hline $\mathrm{O}$ & 43 & 32 & 43.4 \\
\hline $\mathrm{S}$ & $<0.01$ & 1.9 & 0.1 \\
\hline $\mathrm{N}$ & 0.06 & 6.1 & 0.59 \\
\hline $\mathrm{Cl}$ & $<0.01$ & 0.11 & 0.3 \\
\hline \multicolumn{4}{|c|}{ Heating value $\left[\mathrm{MJ} \mathrm{kg}^{-1}\right]$} \\
\hline HHV. daf & 18.9 & 20.4 & 18.4 \\
\hline LHV. raw & 17.4 & 1.9 & 15.6 \\
\hline \multicolumn{4}{|c|}{ Ash analysis [ $\mathrm{g} \mathrm{kg}^{-1}$ dry ash] } \\
\hline $\mathrm{K}$ & 99 & 14 & 110 \\
\hline $\mathrm{Na}$ & 10.6 & 8.3 & 9 \\
\hline Al & 5.9 & 76 & 6.5 \\
\hline $\mathrm{Si}$ & 142 & 142 & 300 \\
\hline $\mathrm{Fe}$ & 8.4 & 162 & 2.1 \\
\hline $\mathrm{Ca}$ & 219 & 44 & 52 \\
\hline $\mathrm{Mg}$ & 33 & 11 & 10 \\
\hline$P$ & 11 & 59 & 14 \\
\hline $\mathrm{Ti}$ & 2.1 & 4.7 & 0.4 \\
\hline
\end{tabular}

daf $=$ dry and ash free, raw $=$ as received $\left(^{*}\right)=$ average thermal behaviour of the zeolite in the temperature range of $700-900^{\circ} \mathrm{C}$ (Möller, 2008). The Doucil A24 samples were pre-treated to simulate zeolites collected in the sewage sludge in a waste water treatment plant. Three Doucil A24 samples were investigated: the original $\mathrm{Na}$ zeolite and the zeolite ion-exchanged with $\mathrm{Ca}^{2+}$ and with Table. 3: Sample matrix of the laboratory tests on zeolites.

$\mathrm{K}^{+}$respectively, Table 3. Due to the

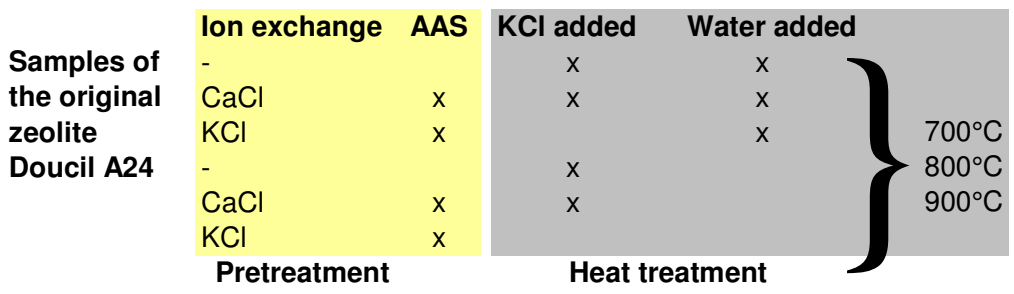
high moisture content in sewage sludge two specimen of each sample material were heated simultaneously, one dry and one with addition of water to simulate the increased amount of water vapour. To investigate the ability of the zeolites to take up potassium during combustion, samples of the original and the Ca exchanged Doucil A24 were heated in the presence of $\mathrm{KCl}$ at 700,800 and $900^{\circ} \mathrm{C}$. Analysis of the samples were made by AAS (Atomic Absorption 
Spectroscopy), XRD and SEM-EDX.

\section{RESULTS AND DISCUSSION}

\section{Element balance}

The element balance over the boiler is shown in Table 4. Especially in the MSS case a good element balance could be achieved. The high outflow of aluminium in the Ref case most likely depends on uncertainty in the results since the molar flow of $\mathrm{Al}$ in this case is low. However, it can not be excluded that a memory effect from previous combustion tests having a high $\mathrm{Al}$ concentration causes these results. In the Ref case $50 \%$ of the chlorine and sulphur entering the boiler were found in the flue gases, Table 4 . In the Zeolite case it was observed that a large fraction of the added zeolites were elutriated by the gas flow through the combustion chamber and predominantly collected in the bag filter fraction.

\section{Deposit formation}

Large differences in deposit formation at the entrance of the convection section (No. 16 in Fig. 1) were found as shown in Fig. 2. The deposit formation rate was reduced by sewage sludge addition and strongly increased by zeolite Table. 4: Element balance over the boiler and element distribution in the ashes of the combustion tests.

\begin{tabular}{lccc|lccc}
\hline Case & Ref & Sludge & Zeolite & \multicolumn{4}{l}{ Case } \\
wt-\%
\end{tabular}
addition. The deposits in the Ref case consisted of fine particles evenly distributed on the windward side of the probe. The colour of the deposits was white with elements of grey. In the MSS case the deposits consisted of a thin dust layer with a reddish brown colour not completely covering the steel surface of the deposit rings. The thickest deposit layers were formed in the Zeolite case. These deposits consisted of white and grey particles and covered the windward side completely.

The results from analyses of the element composition of the deposits are given in Table 5. The Ref case gave deposits mainly consisting of $\mathrm{K}$ and $\mathrm{Cl}$, whereas, the addition of sewage sludge resulted in significant reduction of $\mathrm{Cl}$ and $\mathrm{K}$ in the deposits. Instead the dominating elements in these deposits were $\mathrm{Al}, \mathrm{Ca}, \mathrm{K}, \mathrm{S}$ and $\mathrm{Si}$. The composition of the deposits from the Zeolite case very much reflected the composition of the zeolite powder with the exception that $50 \%$ of the sodium was exchanged for potassium and that
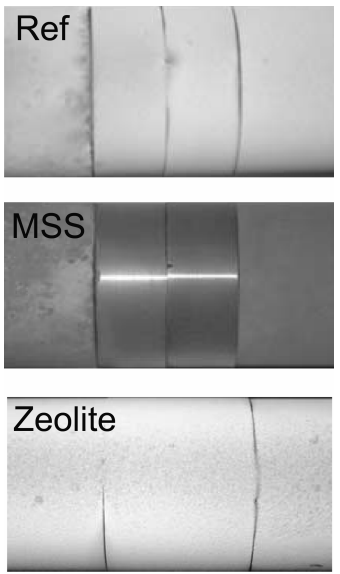

Fig. 2: Deposit probes with rings, windward side. some Ca was found as well. 


\section{Fly ash composition}

The results of the chemical fractionation analysis are presented in Fig. 3. The analysis of the reference fuel mix and fly ashes showed that $\mathrm{Ca}, \mathrm{Mg}, \mathrm{K}$ and $\mathrm{Na}$ were less soluble after combustion, thus transformed into more stable compounds. In contrast, sulphur and chlorine were more soluble in the ash than in the fuel mix. However, the element balances for $\mathrm{K}, \mathrm{Cl}$ and $\mathrm{S}$ were not closed, see Table 4. Part of the reason is that these elements were accumulated as deposits in the convection section of the boiler, (see deposit ring in Fig. 2 and composition in Table 5). In the MSS case the difference between the solubility of $\mathrm{K}$ and $\mathrm{Na}$ in the fuel mix and that in the fly ashes was much larger than in the Ref case, increasing from 8 to $90 \%$ and 35 to $95 \%$ respectively. Chlorine was equally soluble in the fly ashes as in the fuel mix. Sulphur was the only element showing an increased solubility after combustion and no changes in the solubility of aluminium and silicon were found. The fly ash from the zeolite case had the highest $\mathrm{Al}$ and $\mathrm{Na}$ concentrations derived from the original zeolites and most alkali were hard bound in the ash.

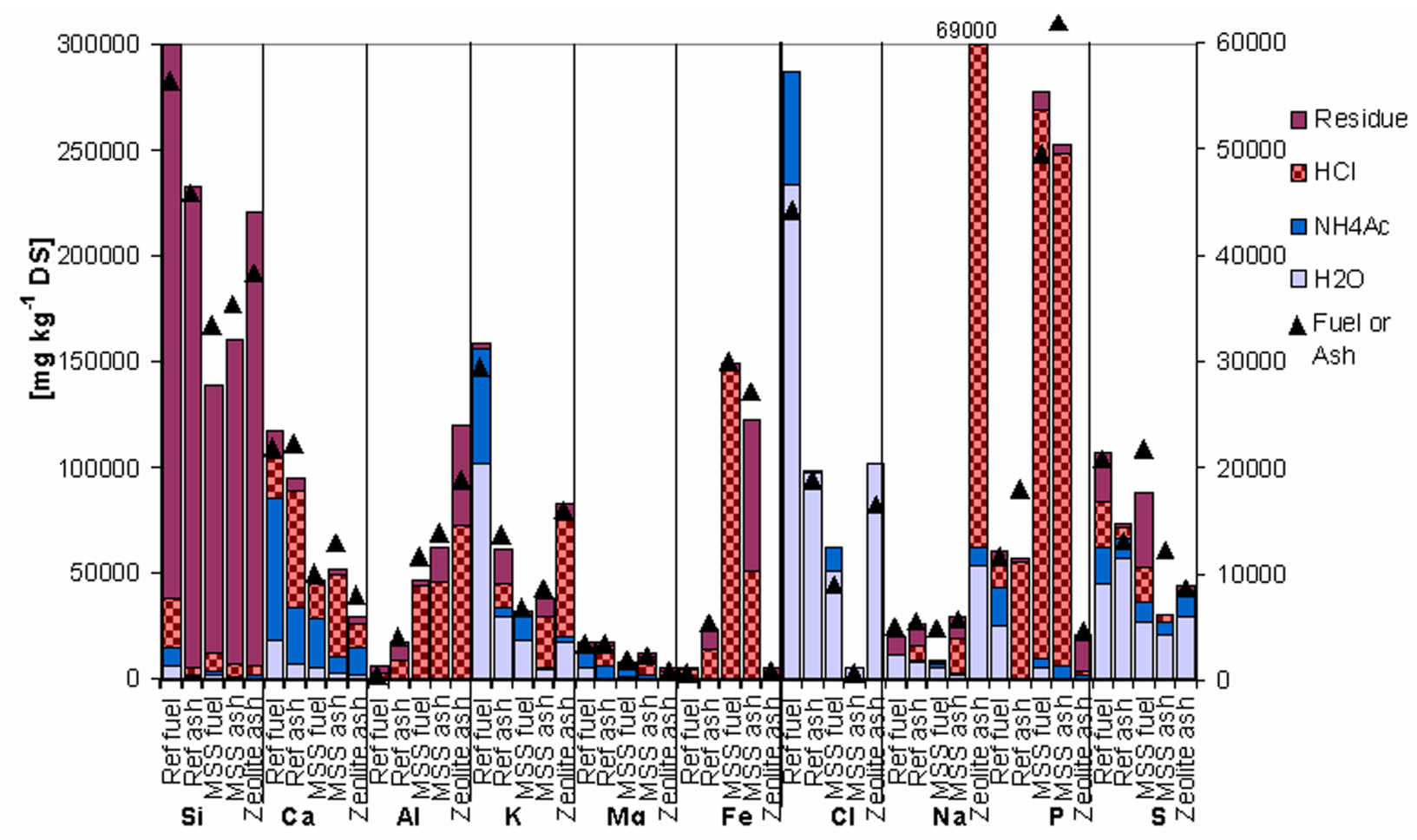

Fig. 3: Fractionation results of fuel mixes and fly ashes (mixture of sec. cyclone and bag filter ashe) from the reference, MSS and zeolite case.

The results from the SEM-EDX mapping of fly ash samples from the three combustion cases are shown in Figs. 4 to 6. In the secondary cyclone ash from the Ref case clear correlations between $\mathrm{K}, \mathrm{S}$ and $\mathrm{Ca}$ were seen, Fig. 4 (Pettersson, 2008). This was also confirmed by the spot analysis (spot 1,4-6). There was also a more diffuse correlation of $\mathrm{K}, \mathrm{Na}$ and $\mathrm{Cl}$ due to the presence of $\mathrm{NaCl}$ and $\mathrm{KCl}$ in small crystals as confirmed by XRD. In addition $\mathrm{K}_{2} \mathrm{SO}_{4}$ and $\mathrm{KAlSi}_{3} \mathrm{O}_{8}$ were found by the XRD analysis (Pettersson, 2008). In the bag filter ash correlations of $\mathrm{K}, \mathrm{Na}$ and $\mathrm{Cl}$ were found and the spot analysis confirmed the higher $\mathrm{Cl}$ and $\mathrm{Ca}$ 
concentrations in this ash. Potassium was more evenly distributed in the bag filter ash and more $\mathrm{KCl}$ was found by the XRD in this ash compared to the secondary cyclone ash. The EDX maps of the fly ash samples from the MSS case are shown in Fig. 5. In this case clear correlations between $\mathrm{Si}, \mathrm{Al}$ and $\mathrm{K}$ were found and also to $\mathrm{P}, \mathrm{Ca}$ and $\mathrm{Fe}$ (Pettersson, 2008). Furthermore, no correlations with $\mathrm{K}$ to $\mathrm{S}$ or $\mathrm{Cl}$ were found. These findings are consistent with results from a study on particle formation in combustion using a low-pressure impactor (Bäfver, 2008). Bäfver and co-workers found $\mathrm{Al}$ and $\mathrm{K}$ only in coarse particles when sewage sludge was added to the fuel mix. In
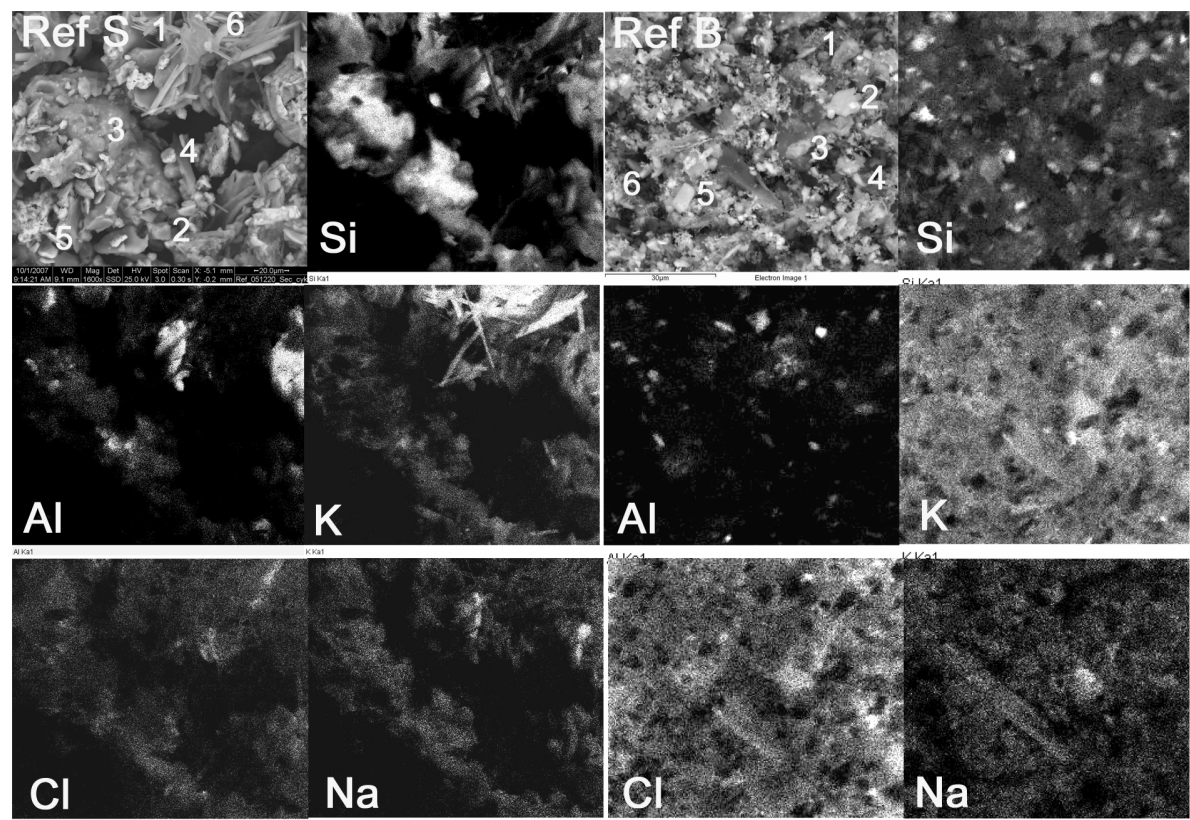

\begin{tabular}{|c|c|c|c|c|c|c|c|c|c|c|c|c|c|c|c|c|c|c|c|c|c|}
\hline \multirow{3}{*}{\multicolumn{2}{|c|}{$\frac{\text { wt- } \% \quad \mathrm{Na}_{2} \mathrm{O}}{\text { Ref Sec. cyc }}$}} & MgO & $\mathrm{Al}_{2} \mathrm{O}_{3}$ & $\mathrm{SiO}_{2}$ & $\mathrm{P}_{2} \mathrm{O}_{5}$ & $\mathrm{SO}_{3}$ & $\mathrm{Cl}$ & $\mathrm{K}_{2} \mathrm{O}$ & $\mathrm{CaO}$ & $\mathrm{Fe}_{2} \mathrm{O}_{3}$ & & $\mathrm{Na}_{2} \mathrm{O}$ & $\mathrm{MgO}$ & $\mathrm{Al}_{2} \mathrm{O}_{3}$ & $\mathrm{SiO}_{2}$ & $\mathrm{P}_{2} \mathrm{O}_{5}$ & $\mathrm{SO}_{3}$ & $\mathrm{Cl}$ & $\mathrm{K}_{2} \mathrm{O}$ & $\mathrm{CaO}$ & $\mathrm{Fe}_{2} \mathrm{O}_{3}$ \\
\hline & & & & & & & & & & & Ref Ba & & & & & & & & & & \\
\hline & 0 & 1 & 1 & 26 & 1 & 34 & 0 & 18 & 17 & 2 & Spot 1 & 1 & 7 & 1 & 45 & 5 & 5 & 1 & 5 & 29 & 1 \\
\hline Spot 2 & 8 & 0 & 9 & 76 & 0 & 0 & 1 & 6 & 1 & 0 & Spot 2 & 0 & 15 & 1 & 27 & 10 & 4 & 1 & 3 & 37 & 2 \\
\hline Spot 3 & 1 & 4 & 0 & 86 & 2 & 0 & 0 & 2 & 4 & 1 & Spot 3 & 1 & 26 & 1 & 14 & 11 & 7 & 3 & 9 & 28 & 1 \\
\hline Spot 4 & 0 & 0 & 0 & 44 & 0 & 57 & 0 & 7 & 9 & 0 & Spot 4 & 1 & 8 & 0 & 31 & 16 & 5 & 1 & 5 & 32 & 1 \\
\hline Spot 5 & 0 & 0 & 0 & 49 & 10 & 0 & 0 & 16 & 25 & 0 & Spot 5 & 0 & 4 & 0 & 8 & 2 & 23 & 2 & 3 & 58 & 1 \\
\hline Spot 6 & 0 & 1 & 0 & 15 & 1 & 48 & 1 & 21 & 19 & 3 & Spot 6 & 0 & 9 & 1 & 28 & 6 & 11 & 3 & 8 & 32 & 2 \\
\hline
\end{tabular}

Fig. 4: SEM-EDX mapping and spot analysis recalculated as oxides (except for chlorine) in wt-\% on fly ashes of the ref. case. S for secondary cyclone ash and B for bag filter ash.

addition, the number of fine particles $(<1 \mu \mathrm{m})$ was significantly reduced compared to combustion of the Ref fuel (the same fuel as in this work). The secondary cyclone ash contained particles only

containing $\mathrm{Si}, \mathrm{Al}$ and $\mathrm{K}$ (as spot 6 in Fig. 5) probably zeolites from the sewage. In addition $\mathrm{Fe}$ and $\mathrm{P}$ correlated well in both these fly ashes. In the XRD analysis potassium and sodium aluminium silicates, sodium silicates, haematite, and phosphates containing $\mathrm{Fe}, \mathrm{Mg}, \mathrm{Ca}$ and $\mathrm{K}$ were found. The EDX results from the zeolite case had the same correlations between $\mathrm{Si}, \mathrm{Al}$ and $\mathrm{K}$ as found in the MSS case, Fig. 6. In addition,

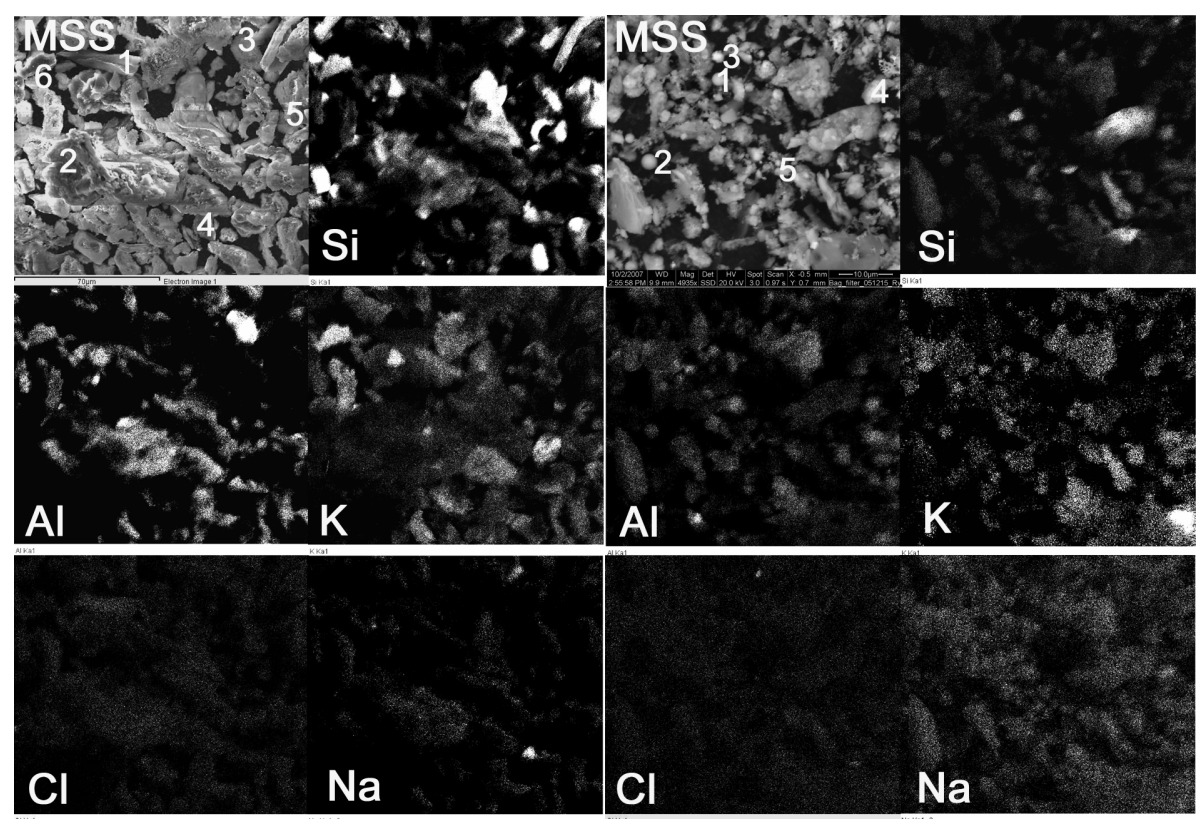

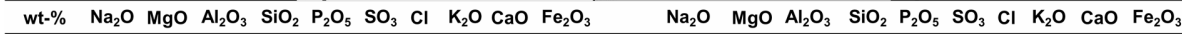

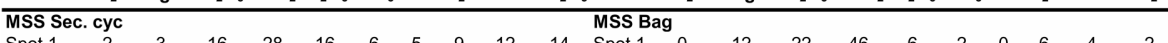
$\begin{array}{llllllllllllllllllllll}\text { Spot 1 } & 2 & 3 & 16 & 28 & 16 & 6 & 5 & 9 & 12 & 14 & \text { Spot 1 } & 0 & 12 & 22 & 46 & 6 & 2 & 0 & 6 & 4 & 2 \\ \text { Spot 2 } & 0 & 2 & 18 & 23 & 17 & 0 & 0 & 2 & 8 & 29 & \text { Spot 2 } & 0 & 11 & 20 & 50 & 4 & 2 & 0 & 7 & 3 & 2\end{array}$ $\begin{array}{llllllllllllllllllllll}\text { Spot 3 } & 1 & 1 & 29 & 31 & 14 & 1 & 0 & 3 & 7 & 15 & \text { Spot 3 } & 2 & 3 & 10 & 21 & 49 & 4 & 0 & 3 & 7 & 1 \\ \text { Spot 4 } & 1 & 2 & 19 & 33 & 20 & 0 & 0 & 4 & 7 & 14 & \text { Spot 4 } & 0 & 4 & 15 & 31 & 21 & 3 & 0 & 7 & 17 & 1\end{array}$ $\begin{array}{lllllllcccccccccccccccc}\text { Spot } 5 & 0 & 1 & 11 & 22 & 18 & 0 & 0 & 9 & 8 & 31 & \text { Spot } 5 & 1 & 3 & 12 & 56 & 14 & 3 & 0 & 4 & 8 & 0 \\ \text { Spot 6 } & 0 & 0 & 17 & 65 & 2 & 0 & 0 & 14 & 1 & 1 & & & & & & \end{array}$

Fig. 5: SEM-EDX mapping and spot analysis recalculated as oxides (except for chlorine) in wt-\% on fly ashes of the MSS case. S for secondary cyclone ash and B for bag filter ash. 
particles with the same composition were found both in the secondary cyclone and bag filter ash.

Furthermore, different $\mathrm{K}$ and $\mathrm{Na}$ aluminium silicates were found by $\mathrm{XRD}$ together with $\mathrm{K}$ and $\mathrm{Ca}$ aluminium silicates and calcium sulphates (Elled, 2008, Pettersson, 2008).

\section{Laboratory experiments}

The ion-exchange of the Doucil A24 to $\mathrm{Ca}$ and $\mathrm{K}$ was established by mixing with a $\mathrm{CaCl}_{2}$ or $\mathrm{KCl}$ solution. Both solutions had a surplus of $\mathrm{Ca}$ or $\mathrm{K}$ ions of approximately ten times the theoretical amount of ion sites in the zeolite sample. The result of the ion exchange and the thermal treatment are
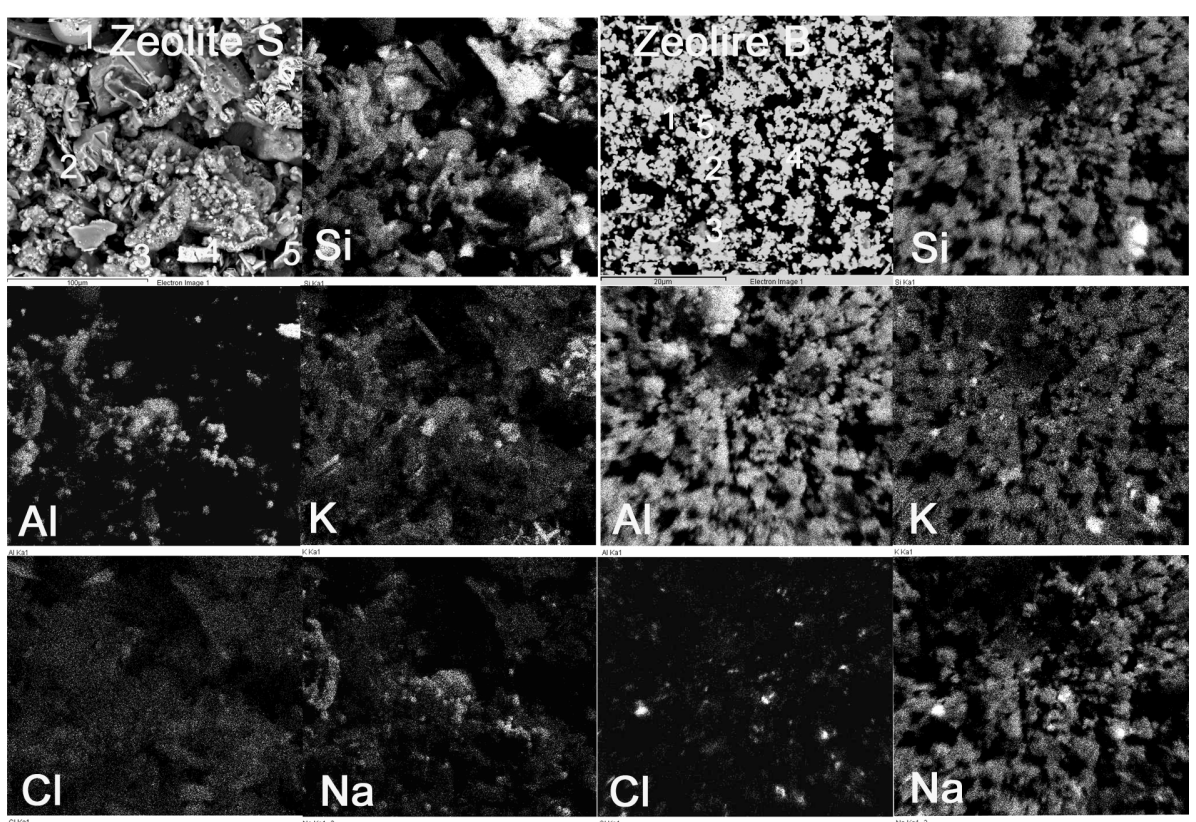

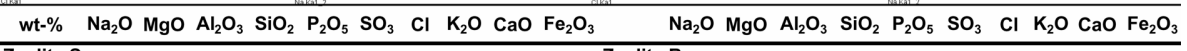
\begin{tabular}{lllllllllllll}
\hline Zeolite Sec. Cyc & & & & & & & & & Zeolite Bag
\end{tabular} $\begin{array}{llllllllllll}2 & \text { Spot } 1 & 1 & 1 & 1 & 88 & 1 & 1 & 1 & 2 & 4 & 0\end{array}$ $\begin{array}{llllllcccccccccccccccc}\text { Spot 2 } & 1 & 1 & 2 & 17 & 0 & 65 & 1 & 22 & 18 & 0 & \text { Spot 2 } & 4 & 0 & 21 & 66 & 1 & 1 & 1 & 4 & 3 & 0 \\ \text { Spot 3 } & 1 & 8 & 5 & 38 & 13 & 1 & 0 & 6 & 22 & 8 & \text { Spot 3 } & 5 & 1 & 5 & 16 & 0 & 7 & 11 & 7 & 48 & 0\end{array}$ $\begin{array}{llllllllllllllllllllll}\text { Spot } 4 & 3 & 5 & 0 & 13 & 1 & 4 & 2 & 4 & 69 & 0 & \text { Spot } 4 & 6 & 0 & 20 & 59 & 1 & 1 & 1 & 9 & 3 & 0\end{array}$ $\begin{array}{llllllllllll}\text { Spot } 6 & 1 & 0 & 25 & 71 & 0 & 0 & 0 & 2 & 0 & 0 & \end{array}$

Fig. 6: SEM-EDX mapping and spot analysis recalculated as oxides (except for chlorine) in $w t-\%$ on fly ashes of the zeolite case. S for secondary cyclone ash and B for bag filter ash.

presented in Table 6. The concentration for Doucil A24 is the theoretical concentration of the pure zeolite and the concentrations for the ion exchanged zeolites are SEM-EDX results from spot and area analysis. The concentrations given in brackets are calculated based on the AAS analysis of the Na concentration in the eluate after the ion exchange. All results in Table 6, except Doucil A24, are mean values of several area or spot analyses of each sample. It was observed that the ion exchanged zeolites had a very uneven distribution of ions over the sample. The reason for this is that MAP zeolites (the group including Doucil A24) have a very flexible structure and the ion exchange rate is increased by increased conversion (Allen et al. 2002), thus isles of high concentrations of $\mathrm{Ca}^{2+}$ or $\mathrm{K}^{+}$ions are formed. This means that an EDX analysis over a larger area of the sample (marked by $*$ in Table 6 ) gives a more accurate mean value than a spot analysis. In the thermal treatment of the original zeolite and the ion exchanged zeolite $0.5 \mathrm{~g}$ of $\mathrm{KCl}$ was added. This corresponds to $6.7 \mathrm{mmol}$ of $\mathrm{K}$ and $\mathrm{Cl}$. The results in Table 6 Table 6: Element composition of the different samples. Results from the SEM-EDX analysis in addition to results from AAS (in brackets).

\begin{tabular}{lccccccc}
\hline [mmol/2g] & $\mathbf{O}$ & $\mathbf{N a}$ & $\mathbf{A l}$ & $\mathbf{S i}$ & $\mathbf{K}$ & $\mathbf{C a}$ & $\mathbf{C l}$ \\
\hline Doucil A24 & 56.3 & 14.1 & 14.1 & 14.1 & - & - & - \\
Ca $_{\text {exchanged }}$ & 68.6 & $0.5[4.1]$ & 11.7 & 12.3 & - & $5.8[5.0]$ & - \\
$\mathbf{K}_{\text {exchanged }}$ & 61.3 & $1.1[2.1]$ & 11.8 & 12.8 & $8.9[12.0]$ & - & - \\
\hline CaKCl 700 & 46,1 & 0,9 & 14,4 & 16,1 & 3,7 & 8,0 & 2,4 \\
CaKCl 800 & 56,6 & 0,4 & 11,2 & 12,3 & 2,4 & 6,4 & 2,4 \\
CaKCl 900* & 55,9 & 0,4 & 7,2 & 6,5 & 5,2 & 9,5 & 3,8 \\
CaKCl 800 steam & 56,6 & 0,4 & 11,3 & 11,7 & 2,8 & 6,0 & 2,9 \\
\hline NaKCl 800* & 48,8 & 7,2 & 10,6 & 11,2 & 6,4 & - & 5,7 \\
NaKCl 800 steam $^{*}$ & 52,7 & 4,1 & 12,0 & 12,7 & 5,6 & - & 4,7 \\
\hline K 900* & 59,3 & 0,8 & 12,6 & 13,2 & 8,3 & - & - \\
K 700 steam* & 66,1 & 0,5 & 13,3 & 14,2 & 4,4 & - & - \\
K 800 steam & 43,8 & 0,2 & 21,9 & 18,4 & 4,7 & - & - \\
K 900 steam & 72,2 & 0,5 & 11,4 & 11,9 & 4,9 & - & - \\
\hline
\end{tabular}

show that the zeolites could capture both $\mathrm{K}$ and $\mathrm{Cl}$ during the heating of the sample. In addition, the original Doucil A24 $(\mathrm{NaKCl})$ captured more $\mathrm{KCl}$ than the $\mathrm{Ca}$ exchanged zeolite $(\mathrm{CaKCl})$. These results were confirmed by the XRD analysis of the samples which showed that both $\mathrm{K}$ and $\mathrm{KCl}$ were incorporated in the zeolite structure. No losses of $\mathrm{Ca}$ were 
detected during the thermal treatment in contrast to $\mathrm{Na}$ where especially the original zeolite lost much of its Na-ions. This could explain the higher capacity of $\mathrm{KCl}$ capture by the original zeolite. The thermal experiments of the potassium exchanged zeolites were performed to investigate the ability of the zeolite to keep the potassium ions even at an increased temperature. The results showed that the zeolite (K in Table 6) encapsulated most of the potassium. Also these results from the EDX varied a lot because of the uneven ion exchange over the sample.

\section{CONCLUSIONS}

Addition of sewage sludge in the combustion of biomass rich in alkali and chlorine gives a significant reduction of the gas phase $\mathrm{KCl}$ level. Addition of zeolites to the boiler gave some smaller reduction of $\mathrm{KCl}$ as well. This indicates similar $\mathrm{KCl}$ absorption mechanisms. The laboratory study shows that $\mathrm{KCl}$ can be captured as a whole in the zeolite structure at high temperatures, probably by encapsulation when the structure is starting to change due to the heating.

The chemical fractionation showed that potassium and sodium are less soluble in the fly ash after combustion of the MSS fuel mix than in the reference case. This can be explained by the formation of aluminium silicates containing alkali metal ions, like feldspars.

\section{REFERENCES}

Allen, S., Carr, S., Chapple, A., Dyer, A. and Heywood, B.: PCCP 4 (2002), pp. 2409-2415.

Bäfver, L. (2008). PhD thesis, Chalmers University of Technology, Sweden, ISBN 978-91-7385-177-0.

Davidsson, K. O., Åmand, L.-E., Elled, A.-L. and Leckner, B.: Energy and Fuels 21 (2007), pp 3180-3188.

Elled, A-L. (2008) PhD thesis. Department of Energy and Environment, Chalmers university of Technology, ISSN 0346-718X, ISBN 978-91-7385-139-8.

Elled, A.-L., Åmand, L.-E. and Davidsson, K. (2008) Effects from co-firing municipal sewage sludge with biomass on deposit formation. Submitted to Biomass and Bioenergy.

Eriksson, J. (2001). Report 5159, Swedish Environmental Protection Agency, Stockholm, ISBN 91-620-5159-8, ISSN 0282-7298.

ICCP, (2007). Climate change 2007: Mitigation. Contribution of Working group III to the Fourth Assessment Report of the Intergovernmental Panel on Climate Change [B. Metz, O. R. Davidson, P .R. Bosch, R. Dave, L. A. Meyer (eds)], Cambridge University Press, Cambridge, United Kingdom and New York, NY, USA.

Möller, A. (2008). Chalmers University of Technology, Göteborg, Sweden, Report nr. T2008-310.

Pettersson, A. (2008) PhD thesis. Department of Energy and Environment, Chalmers university of Technology, ISSN 0346-718X, ISBN 978-91-7385-174-9.

Pettersson, A., Zevenhoven, M., Steenari, B.-M., Åmand, L.-E.: Fuel 87 (2008), pp 3183-3193.

Schwuger, M. J. Detergents in the environment. 1996, ISBN 0-8247-9396-X.

Zevenhoven-Onderwater, M. (2001). PhD thesis. Department of Chemical Engineering, Åbo Akademi University, Finland, ISSN 1457-7895, ISBN 952-12-0813-9. 